\title{
DETERMINAÇÕES ESTRATÉGICAS E POTENCIALIDADES DE TRANSFORMAÇÃO DO PROGRAMA FAVELA-BAIRRO*
}

\author{
RAINER RANDOLPH ${ }^{* *}$ \\ Universidade Federal do Rio de Janeiro
}

\section{Marcos conceituais para a análise das determinações estratégicas e potencialidades de transformação ${ }^{1}$}

A elaboração dos fundamentos metodológicos de uma avaliação do Programa Favela-Bairro um programa de urbanização de favelas, iniciado em 1993/94 pela então administração municipal do Rio de Janeiro -, obrigou-nos a analisar os processos de formulação e reformulação de suas metas, objetivos, proposições, medidas etc.. Tal análise levou-nos a questionamentos cada vez mais profundos e abrangentes, ao mesmo tempo em que apontou para uma série de inconsistências e contradições.

\section{Questionamentos}

Não é que as contradições ou inconsistências entre discurso político e prática administrativa nos surpreendessem ${ }^{2}$, mas são dignas de nota pois podem oferecer a chave de acesso aos processos políticos, via de regra, pouco transparentes. Despertaram, portanto, nosso interesse em buscar responder às seguintes indagações: como lidar com o fato de que, ao nível do discurso dos políticos, o Programa foi anunciado como política de "integração das favelas aos bairros", quando a orientação concreta e administrativa do Programa parece ser melhorar as condições de vida da população favelada e propiciar uma leitura da favela como bairro?; como compreender a coincidência surpreendente da "intenção integradora" como aquela encontrada no Plano Diretor da Cidade, quando a Prefeitura esteve empenhada em criar um novo "pacto municipal" (entre os citadinos cariocas) por intermédio de um Plano Estratégico?; como entender a centralidade política atribuída ao Programa pela antiga e a nova administração do município (a partir de 1997), quando se observa a inserção nada destacada do Programa nas estratégias, ações e projetos do

\footnotetext{
* Uma primeira versão deste ensaio foi apresentada na III. SEMANA IPPUR, na 1a Mesa "Rio de Janeiro: uma metrópole sob vivissecção", 9 a 12.12.96, IPPUR/UFRJ, Rio de Janeiro; sofreu modificações no decorrer do tempo com a incorporação parcial - não sistemática - das próprias transformações do Programa.

** Dr. rerum politicum Universidade de Erlangen-Nueremberg. Professor do Instituto de Pesquisa e Planejamento Urbano e Regional da Universidade Federal do Rio de Janeiro. Pesquisador do CNPq.

$1 \mathrm{O}$ atual trabalho é um dos resultados do projeto "Avaliação de Políticas Sociais. Fundamentos Metodológicos para um Plano de Avaliação do Programa Favela Bairro", que fez parte de uma cooperação interinstitucional que contou com recursos da FINEP e da Prefeitura da Cidade do Rio de Janeiro e resultou em um extenso relatório (Vide RANDOLPH, 1996a).

2 Os autores críticos ao sistema capitalista já deixaram claro o suficiente que isto é uma conseqüência funcional (e não disfuncional) de o Estado legitimar-se para TODOS os segmentos sociais da sociedade - vide em particular a discussão de Offe (1994: 140-177) - porém, a incoerência e inconsistência podem criar problemas para o poder, na medida em que lhe retiram sua credibilidade e legitimidade.
} 
Plano Estratégico?

O atual trabalho originou-se, então, de nossa curiosidade em "compreender" o Favela Bairro para além de suas "realizações" imediatas. Pretendíamos situá-lo dentro de um quadro político mais geral que facultasse desvendar suas determinações e importância estratégicas e sua potencialidade para uma transformação "real" do tecido social e urbano da Cidade do Rio de Janeiro.

Para encararmos este desafio, necessitamos de poderosos instrumentos de análise que permitam articular nossos questionamentos específicos com uma visão conceitual do Estado contemporâneo. E, mesmo quando os conceitos não se adaptam integralmente à realidade brasileira, podem nos dar pistas para descobrir as especificidades de nossa realidade. No caso em pauta recorremos a abordagens da sociologia política e, em particular, à conceituação de Offe.

\section{Projetos políticos e arenas de disputas}

Como sabemos, desde Offe (1994), o capitalismo (minimamente) organizado, em sua fase ainda incipientemente globalizada, não prescindia de um "Estado" como lugar de articulação de um projeto "global" (nacional) das diversas correntes, facções e setores do(s) capital(ais) que tanto "disciplinavam" seus próprios correligionários, como serviam de bastão contra reivindicações de seus opositores - da classe trabalhadora - que podiam colocar em risco o próprio sistema (OFFE, 1994: 140-177). O exercício do poder como político - e não de classe - o obrigava a desmentir seu verdadeiro caráter através de um mecanismo sofisticado de "seletividades" institucionalizadas e baseadas numa teia intransparente de relações entre interesses, forças e arenas políticos que, por sua vez, "neutralizava" as contradições sóciopolíticas através de mecanismos formais de exercício democrático, em poucos momentos, e da lealdade a este sistema de representação por amplos setores da população durante os períodos intersticiais. $\mathrm{O}$ atendimento - seletivo e parcial - às prerrogativas das classes e segmentos sociais subalternos $^{3}$ fazia parte de uma estratégia de legitimação deste poder.

É lugar comum que o Brasil jamais experimentou o Estado social em moldes europeus; obviamente as propostas neoliberais que surgem entre nós nos últimos anos estão inseridas num contexto bem diverso daquele dos países industrializados. Mesmo assim, parece interessante observar a história alheia por estarmos confrontados com alternativas que se discute também para o caso brasileiro.

Offe propõe que os processos políticos poderão "ser melhor compreendidos, se os imaginamos compostos de três níveis ou três arenas de conflitos, dispostas uma sobre a outra" (OFFE, 1991: 128):

1. "A primeira e mais fácil de reconhecer é a arena dos processos políticos das decisões no interior do aparato estatal. Os seus protagonistas são as elites políticas que concorrem entre si pelas vitórias eleitorais e pelos escassos recursos. Elas decidem sobre programas político-sociais, legislação e orçamentos. Este é o nível superficial e visível da política, aquele que chega às massas, e que sempre está em jogo, quando os cidadãos são instados a agir em seu papel político, como, por exemplo, no de eleitor"(idem: 128 e ss);

2. Na medida em que o espaço disponível para as decisões das elites políticas é determinado por forças sociais, existe um outro nível (por baixo do mencionado) em que se produz, distribui e institui o poder político. As mencionadas forças sociais, de uma forma bem menos visível, "influenciam as opiniões dos políticos e as suas percepções da

3 Segundo Offe, a paz social nas democracias capitalistas desenvolvidas foi conquistada, primeiro, através do mecanismo estatal de proporcionar assistência e apoio (em dinheiro ou em serviços) aos cidadãos que caem em miséria ou sofrem riscos especiais" e, segundo, mediante o "reconhecimento do papel formal dos sindicatos tanto nas negociações coletivas entre capital e trabalho quanto no processo de formação da vontade política" (1991:113). 
realidade e, assim, as alternativas que estão abertas às decisões políticas e as conseqüências que podem ser esperadas de cada uma das alternativas". É aqui que se determina tanto a agenda política e prioridade relativa dos temas políticos, como também as soluções dos problemas e a durabilidade dos pactos e compromissos. Apesar de uma certa intransparência na identificação de indivíduos que manipulam estas determinações, há "uma matriz do poder social, segundo a qual certas classes sociais, atores coletivos e outras categorias sociais têm chance maior do que outros para formar e mudar a realidade política e assim cunhar a agenda e o espaço das decisões das elites políticas” (idem: 129). A distribuição desigual dentro da estrutura social do acesso aos meios de produção, organização e comunicação e seu controle será aplicada, com diferentes graus de eficácia, para formar aquilo que os políticos visualizam como seu campo de decisão;

3. Por baixo deste segundo nível da política, existe um terceiro no qual ocorrem as mudanças no interior da própria matriz social; são transformações que alteram os "pesos" relativos que os atores coletivos possuem na formação do campo de decisão (dos temas políticos); trata-se aqui das posições de poder social que são questionadas, objeto de mudanças e redistribuição. "O que ocorre no terceiro e mais importante nível da política, é a luta pela redistribuição do poder social. O poder do mercado, a legitimidade política ou a força de organização que um grupo ou uma classe usufrui, durante certo tempo, podem, por exemplo, ser reduzidos (...), ou outro grupo pode abrir para si novos canais de influência, formar novas alianças ou conquistar posição hegemônica mediante referência a valores, ideais e visões novos" (idem: 130).

Finaliza o autor sua reflexão com o alerta de que as interrelações entre os três níveis não são estritamente hierárquicas, mas circulares: "embora o espaço de ação do primeiro nível ('política formal') seja em grande parte, determinado pela matriz do poder social ('segundo nível'), é ele próprio capaz de facilitar e promover uma revisão das bases normativas e das interpretações da distribuição do poder social ('terceiro nível'). E, por isso, o palco da política democrática deveria ser concomitantemente considerado como determinado pelo poder social e como determinante dele" (idem: 131).

Acreditamos que a importância da última gestão municipal do Rio de Janeiro - e em particular uma das suas políticas carro-chefe: o Programa Favela Bairro - pode ser analisada dentro de um marco conceitual próximo à proposta de Offe. Mais ainda, partimos do pressuposto de que suas determinações estratégicas e suas potencialidades de transformação apenas podem ser compreendidas quando observado o Programa nas três arenas há pouco referidas.

\section{Plano diretor e formulação do programa Favela-Bairro}

Ao nível dos discursos eleitorais já de duas eleições seguidas e da divulgação pela mídia, o Programa Favela-Bairro da Prefeitura da Cidade do Rio de Janeiro está sendo identificado enquanto proposta de integrar a favela ao bairro. Seria, inclusive, o projeto de integração que o distingue, como dizem os políticos (e escrevem os jornais), de inúmeras tentativas anteriores de urbanizar as favelas do Rio de Janeiro. De onde vem este objetivo e até que ponto ele está sendo realmente observado pelo Programa é o assunto do atual item.

\section{Formulação do Programa}

Antes de procurar as origens, julgamos importante caracterizar rapidamente o Programa Favela-Bairro e introduzir os objetivos como foram se consolidando após uma primeira fase de "experimentação" (concurso público). 
O Programa surgiu em 1993, no governo municipal do Rio de Janeiro como um dos elementos da política habitacional, conforme as "Bases da Política Habitacional da Cidade do Rio de Janeiro", e pretendia "complementar ou construir a estrutura urbana principal (saneamento e democratização do acesso) e oferecer condições ambientais de leitura da favela como bairro". Consolidou-se como Programa de Urbanização de Assentamentos Populares do Rio de Janeiro PROAP -, instituído pelo Decreto 14.332 de 07/11/1995, que articulava o Programa Favela Bairro (que teve sua base legal estabelecido pelo Decreto 12.994, de 16/06/94) com o Programa de Regularização de Loteamentos, além de tomar outras providências. A parte referente ao "FavelaBairro" reproduz exatamente os objetivos que constaram nos documentos anteriores.

$\mathrm{O}$ contrato de empréstimo entre Prefeitura e $\mathrm{BID}^{4}$ consolidou os recursos necessários para sua execução. Conforme o Anexo A deste contrato, seus três componentes seriam a urbanização de favelas", a "regularização de loteamentos" e o terceiro componente dividia-se em "(i) monitoramento e avaliação, (ii) educação sanitária e ambiental e (iii) desenvolvimento institucional".

O PROAP e contrato de empréstimo com o BID determinam o porte das favelas que podem ser contempladas pelo Programa: não serão atendidas favelas com menos de 500 e mais de 2.500 domicílios $^{5}$. Dentro desta faixa - excluindo favelas que fazem parte dos maiores complexos da cidade (Maré e Morro do Alemão) - encontravam-se 100 favelas, com 410.781 moradores distribuídos entre 100.853 domicílios, conforme um cálculo provisório realizado na base de dados do IBGE (Censo Demográfico de 1991). Isto corresponde a aproximadamente $43 \%$ de todos os domicílios em favelas no município do Rio de Janeiro.

É interessante notar que entre favelas de grande e menor porte, a população está distribuída quase eqüitativamente: aproximadamente $25 \%$ nas 15 favelas e complexos de grande porte e $27 \%$ nas inúmeras pequenas favelas (mais do que 440).

O PROAP pretende atender cerca de sessenta favelas, beneficiando aproximadamente 220.000 pessoas, o que corresponde a quase $60 \%$ do universo das favelas de porte médio. Uma breve análise das favelas que já foram selecionadas para integrar as quatro fases do Programa mostra que o critério do tamanho foi sendo seguido com raras exceções (basicamente, quando se trata dos assim chamados "complexos" de favelas são incluídas também favelas de menor porte junto a outras de tamanho médio).

\section{Os objetivos do Programa}

Toda atuação por parte das entidades envolvidas ${ }^{6}$ está orientada pelos objetivos, propósitos e componentes do Programa ${ }^{7}$. Em relação à suas metas, o PROAP-RIO e outros documentos principais $^{8}$ (inclusive de elaboração "coletiva" entre as diferentes secretarias da Prefeitura) falam claramente na melhoria das condições de vida, sociais e ambientais da população de baixa renda do Município do Rio de Janeiro; ou, no máximo, referem-se a comparações entre favela e bairro onde "o bairro" pode ser compreendido como padrão normal (standard) da intervenção; tanto em termos objetivos como subjetivos. Aponta como principal meio para o seu alcance o aumento da

4 As negociações com o BID dão origem a alguns documentos que são básicos para a compreensão do Programa; particularmente, o esforço conjunto da Prefeitura com consultores do Banco em elaborar o MARCO LÓGICO teve grande influência na consolidação do Programa.

5 Existem outros critérios de "pré-elegibilidade", que não serão explicitados aqui (vide RANDOLPH, 1997).

6 A unidade executara do PROAP-RIO e de todas as articulações inter-setorias entre diferentes órgãos setoriais da própria Prefeitura é a Secretaria Municipal de Habitação; ela realizará a coordenação intenrinstitucional do Programa, com o apoio permanente do GEAP.

7 Vide a discussão mais explícita em uma outra análise nossa (RANDOLPH, 1997) sobre os objetivos do Programa.

8 De maior importância mostrou-se o assim chamado Marco Lógico, que foi elaborado como síntese dos principais objetivos do Programa por ocasião de uma reunião entre todos as secretárias municipais envolvidas e consultores do BID. 
oferta de infra-estrutura básica e de serviços sociais à população residente em favelas e loteamento irregulares.

Procuramos organizar os objetivos, a fim de poder representá-los sistemática e sinteticamente, em dois eixos: por um lado serão identificados certas esferas ou setores de intervenção do Programa; por outro, procura-se atribuir às medidas algum nível ou escala sócioespacial de suas possíveis conseqüências (seus destinatários). A construção de uma matriz a partir destes dois eixos mostra, na página seguinte, uma gama relativamente ampla e complexa das pretensões do Programa Favela-Bairro.

Concluímos que o Programa procura modificar as

i. condições do bem estar individual, da convivência coletiva e da organização social tanto no patamar dos próprios moradores como de suas articulações coletivas;

ii. condições gerais de habitabilidade que se referem aos equipamentos e serviços disponíveis junto à moradia de cada família:

iii. condições estruturais de sobrevivência nos mercados formais na medida em que se preocupa com o patrimônio imobiliário da população;

iv. condições de circulação e encontros públicos;

v. condições ambientais e de segurança;

vi. condições de equipamentos coletivos à disposição da população favelada e acesso a serviços públicos como educação e saúde; e, finalmente, as

vii. condições de regulação da vida pública e privada que se refere a regulações urbanísticas, reconhecimento de direitos de propriedade e de trabalho etc.

É preciso distinguir entre os objetivos principais, que são explicitamente atribuídos ao Programa, e objetivos complementares, que constam na acima mencionada terceira componente do PROAP.

A viabilização operacional do programa é assegurada por um "Caderno de Encargos" que desdobra estes objetivos em regras bastante específicas que precisam ser seguidas na elaboração dos projetos para cada favela.

Os critérios de seleção das favelas, que podem entrar no Programa Favela-Bairro (na sua face de articulação com o BID), podem ser compreendidos como outra determinação estratégica que limitam sua atuação e significam uma previdência prudente contra um desafio exagerado que aumentaria o risco de seu fracasso.

\section{Comparação com o Plano Diretor}

O Plano Diretor Decenal da Cidade do Rio de Janeiro foi aprovado como Lei Complementar $\mathrm{n}^{\circ} 16$, de 04/06/1992, ainda na gestão anterior àquela que cria o Programa Favela-Bairro, e contém uma série de disposições relativas à política urbana. Entre os programas prioritários da política habitacional do município, consta um explicitamente a respeito da urbanização e regularização fundiária de favelas (dentro do Art. 146, o inciso 1, e os parágrafos deste artigo).

Favela, conforme o Art 147, é uma área predominantemente habitacional, com ocupação por população de baixa renda, precariedade da infra-estrutura e de serviços públicos, vias estreitas e de alinhamento irregular, lotes de forma e tamanho irregular e construções não licenciadas em desconformidade com os padrões legais. A intervenção será orientada por estudo da situação fundiária e projeto urbanístico que deverão observar as seguintes orientações (Art. 152):

- "integração da favela ao bairro e ao aglomerado de favelas onde está situada" (sic!!);

- "preservação da tipicidade da ocupação do local; 
- previsão da implantação progressiva e gradual da infra-estrutura

O parágrafo $1^{\circ}$ deste artigo versa sobre a regularização urbanística e estabelece instrumentos de sua realização; já os parágrafos $2^{\circ}$ a $5^{\circ}$ estabelecem normas, regras, campos de intervenção etc. da própria urbanização. Confere prioridades à implantação de abastecimento de água, esgotamento sanitário, remoção de resíduos sólidos e à "eliminação dos fatores de risco". Prevê ações complementares (em relação a vias, drenagem, iluminação, projetos de alinhamento e reflorestamento) e equipamentos complementares (saúde, educação, lazer e outros), bem como a instalação de escritórios técnicos locais que poderão, após o término das obras, prestar assistência técnica e social aos moradores.

Ao nível das propostas concretas de urbanização, uma comparação mais detida, mostraria que uma série destes dispositivos mais específicos do Plano Diretor encontra-se quase identicamente no Programa Favela-Bairro. Já a regularização urbanistica não mereceu a mesma prioridade por parte do Programa.

\begin{tabular}{|c|c|c|c|c|c|c|c|}
\hline \multirow[b]{2}{*}{ Destinatários/ escalas } & \multicolumn{7}{|c|}{ Esferas de intervenção } \\
\hline & $\begin{array}{l}\text { condições do bem } \\
\text { estar individual, } \\
\text { convivência } \\
\text { coletiva o } \\
\text { organização social }\end{array}$ & $\begin{array}{l}\text { condições } \\
\text { gerais de } \\
\text { habitabilidade } \\
\\
\text { (equipamentos } \\
\text { e serviços de } \\
\text { infraestrutura } \\
\text { junto à } \\
\text { moradia) }\end{array}$ & $\begin{array}{l}\text { condições } \\
\text { estruturais de } \\
\text { sobrevivência }\end{array}$ & $\begin{array}{l}\text { condições de } \\
\text { circulação e } \\
\text { encontros } \\
\text { públicos } \\
\text { (condições } \\
\text { físicas gerais) }\end{array}$ & $\begin{array}{l}\text { condições } \\
\text { ambientais e de } \\
\text { segurança } \\
\text { (inclusive } \\
\text { salubridade) }\end{array}$ & $\begin{array}{l}\text { condições de } \\
\text { equipamentos } \\
\text { coletivos e } \\
\text { serviços } \\
\text { públicos de } \\
\text { saúde e } \\
\text { educação }\end{array}$ & $\begin{array}{l}\text { condições de } \\
\text { regulação da } \\
\text { vida pública e } \\
\text { privada por } \\
\text { parte do poder } \\
\text { público } \\
\text { (direitos) }\end{array}$ \\
\hline $\begin{array}{l}\text { Contexto urbano } \\
\text { (favela e/ou bairro) }\end{array}$ & & $\begin{array}{l}\text { * regularização } \\
\text { urbanística da } \\
\text { situação } \\
\text { (padrões } \\
\text { construtivos e } \\
\text { urbanísticos) }\end{array}$ & & $\begin{array}{l}* \text { vias de } \\
\text { acesso } \\
\text { principais }\end{array}$ & $\begin{array}{l}\text { * eliminação de } \\
\text { riscos } \\
\text { ambientais } \\
\text { (deslizamento, } \\
\text { enchentes etc.) } \\
\text { *reflorestamento }\end{array}$ & & $\begin{array}{l}\text { * regularização } \\
\text { urbanística da } \\
\text { situação } \\
\text { (padrões } \\
\text { construtivos e } \\
\text { urbanísticos) } \\
\text { direitos civil e } \\
\text { político }\end{array}$ \\
\hline $\begin{array}{c}\text { Coletivo } \\
\text { (Comunidade) }\end{array}$ & $\begin{array}{l}\text { * normas da } \\
\text { regularização } \\
\text { urbanística da } \\
\text { situação (padrões } \\
\text { construtivos e } \\
\text { urbanísticos) } \\
\text { * acesso a praças } \\
\text { *maior frequêencia } \\
\text { de eventos } \\
\text { comunitários }\end{array}$ & $\begin{array}{l}\text { * vias de } \\
\text { acesso } \\
\text { * iluminação } \\
\text { pública } \\
\text { * coleta de lixo }\end{array}$ & & $\begin{array}{l}\text { * vias de } \\
\text { acesso } \\
\text { secundárias } \\
\text { * iluminação } \\
\text { * praças } \\
\text { * quadras de } \\
\text { esportes }\end{array}$ & $\begin{array}{l}\text { * redes de água } \\
\text { e esgoto } \\
\text { (extinguir valas } \\
\text { abertas de } \\
\text { esgoto) } \\
\text { * drenagem } \\
\text { * coleta de lixo } \\
\text { iluminação } \\
\text { pública }\end{array}$ & $\begin{array}{l}\text { * quadras de } \\
\text { esporte } \\
\text { * creches } \\
\text { * centros } \\
\text { comunitários } \\
\text { * educação } \\
\text { sanitária e } \\
\text { ambiental } \\
\text { (agentes } \\
\text { comunitários) }\end{array}$ & \\
\hline $\begin{array}{l}\text { Moradores/domicílios } \\
\text { (famílias, população) }\end{array}$ & $\begin{array}{l}\text { * titularização } \\
\text { (complementar) } \\
\text { * consciência } \\
\text { ambiental } \\
\text { (educação) } \\
\text { * exercícios } \\
\text { esportivos } \\
\text { (quadras de } \\
\text { esporte) } \\
\text { * satisfação, } \\
\text { percepção (efeito) }\end{array}$ & $\begin{array}{l}\text { * água } \\
\text { (ligações, } \\
\text { freqüência); } \\
\text { * esgoto }\end{array}$ & $\begin{array}{l}\text { * patrimônio } \\
\text { através da } \\
\text { valorização } \\
\text { imobiliária } \\
\text { (efeito) }\end{array}$ & & $\begin{array}{l}\text { * redução da } \\
\text { veiculação } \\
\text { hídrica de } \\
\text { doenças } \\
\text { * redução na } \\
\text { percepção da } \\
\text { violência }\end{array}$ & & $\begin{array}{l}\text { * preparativos } \\
\text { para a } \\
\text { titularização } \\
\text { (direito civil) } \\
\text { (complementar) }\end{array}$ \\
\hline $\begin{array}{l}\text { Segmentos da } \\
\text { população: }\end{array}$ & $\begin{array}{l}\text { * geração de } \\
\text { renda } \\
\text { (através de } \\
\text { cooperativas) }\end{array}$ & & $\begin{array}{l}\text { * geração de } \\
\text { renda (através } \\
\text { da inserção nos } \\
\text { mercados) }\end{array}$ & & & & $\begin{array}{l}* \text { geração de } \\
\text { renda } \\
\text { (direito social) } \\
\text { (complementar) }\end{array}$ \\
\hline adultos & (complementar) & & $\begin{array}{l}\text { - Seminários } \\
\text { (complementar) }\end{array}$ & & & & \\
\hline
\end{tabular}




\begin{tabular}{|c|c|c|}
\hline crianças & $\begin{array}{l}\text { * cuidados às } \\
\text { crianças } \\
\text { através de } \\
\text { creches: } \\
\text { - vacinação, } \\
\text { educação, } \\
\text { nutrição }\end{array}$ & $\begin{array}{l}\text { * documentos } \\
\text { básicos de } \\
\text { registro } \\
\text { (direito civil) }\end{array}$ \\
\hline
\end{tabular}

Ou seja, por um lado, encontramos na formulação do Programa Favela-Bairro uma apropriação aparentemente "incoerente" do Plano Diretor na medida em que mantém o discurso da "integração" ao nível dos pronunciamentos políticos. mas negligencia uma parte substancial de uma possível integração - a regularização urbanística ${ }^{9}$ - e, relacionada a esta, a regularização fundiária. Por outro lado, assegura, ao nível da administração política do Programa, sua operacionalidade na medida em que produz para as intervenções de urbanização, já previstas no Plano Diretor, um discurso "coerente" - mais "realista" - da melhoria das condições de vida da população favelada.

Como compreender, então, esta complexa trama de continuidade/descontinuidade ou coerência/incoerência? É nossa hipótese de que nela se expressa uma "lógica" de uma modificação da matriz do poder social entre o período da elaboração e aprovação do Plano Diretor e a formulação do Programa Favela-Bairro. Acreditamos que melhor se pode identificar esta reformulação a partir do estudo do Plano Estratégico da Cidade do Rio de Janeiro (PECRJ) que foi sendo desenvolvido paralelamente ao Programa (de 1993 a 1995).

\section{Programa Favela-Bairro e Plano Estratégico}

Parece-nos, portanto, a elaboração do PECRJ o momento chave para investigar a matriz de poder social, um novo "acordo estratégico" (vide nossa análise em RANDOLPH, 1996), de um projeto político que se pretende hegemônico e que incorpora o Programa Favela Bairro na sua "ageada", seu campo de decisões, selecionando uma determinada parcela das determinações previstas no Plano Diretor.

\section{Localização do Programa Favela-Bairro dentro das estratégias do PECRJ}

O Plano Estratégico estabelece um objetivo central como marco de referência globalizador que traduz o "acordo de todas as instituições-membros no sentido de avançar numa mesma direção". É objeto deste acordo uma compreensão "consensual" que pretende "tornar o Rio de Janeiro uma metrópole com crescente qualidade de vida, socialmente integrada, respeitosa da coisa pública e que confirme sua vocação para a cultura e a alegria de viver. Uma metrópole empreendedora e competitiva, com capacidade para ser um centro de pensamento, de geração de negócios para o país e sua conexão privilegiada com o exterior" (grifo nosso) (Prefeitura da Cidade do Rio de Janeiro 1996: 23). Procurou-se, conforme se explicita neste objetivo, buscar o compromisso entre lógica da cidadania e lógica do mercado.

Desdobrado o objetivo central em sete estratégias, estas representam os temas-chave da cidade; por sua vez descompostos em objetivos e ações.

Uma dessas estratégias é do "Rio integrado" que tem como um de seus objetivos a "normalização urbanística": uma das ações para realizar este objetivo chama-se "normalizar a situação urbanística" e tem o Programa Favela Bairro como um de seus projetos. Estamos, portanto, diante de uma hierarquia de relações meios - fins (cada objetivo a nível inferior torna-se

9 O primeiro documento - as "Bases da Política Habitacional" - ainda falava da regularização urbanística como meio de integração. 
meio para o superior) que podemos visualizar da seguinte maneira:

Ou seja, o Programa aparece aqui como último de uma cadeia de elementos dentro da estratégia do "Rio Integrado" que contribuirá à transformação do Rio de Janeiro numa cidade competitiva internacionalmente. Partimos do pressuposto de que transparecem aqui acordos que vão muito além (ou "aquém", conforme a idéia das arenas) do patamar político formal, que constituem o projeto de uma determinada articulação de forças sociais.

\section{Objetivo Central Estratégias Objetivos Ações $\quad$ Projetos}

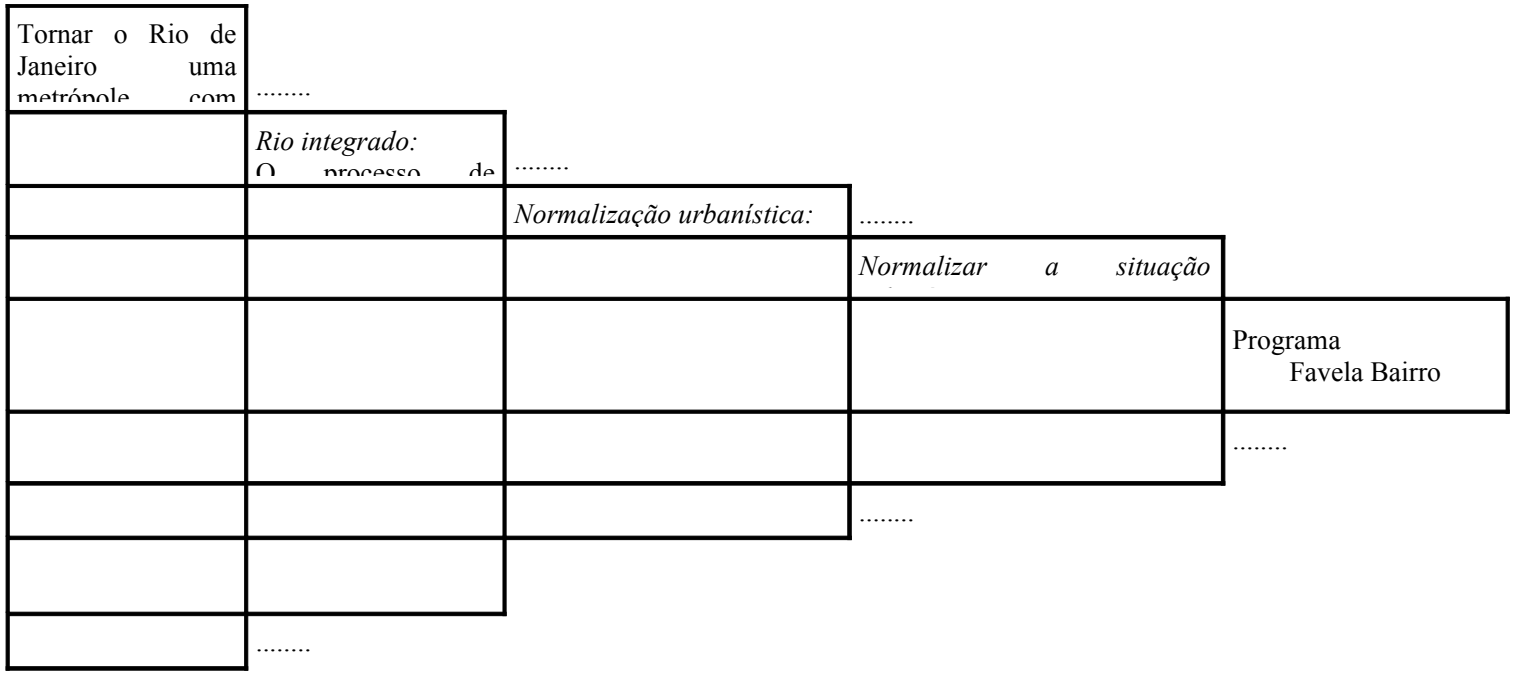

É nossa hipótese que a importância, que lhe foi atribuída pelos políticos e pelo público em geral, tem sua origem na constelação dos novos acordos (uma nova matriz do poder social) que já não se preocupa mais em elaborar um projeto universal pelo menos aparentemente coerente como se viram obrigados os "governos modernos" -, mas aposta em ações pontuais, porém, acompanhadas por um intensivo esforço de "publicização" através de uma atuação sistemática de presença e divulgação nas mídias de massa.

\section{A formulação do PECRJ e indicações da matriz de poder social ${ }^{10}$}

Não nos pretendemos alongar no estudo das justificativas daqueles que propagam o planejamento estratégico. Interessa dentro do nosso tema a elaboração do Plano que revelará a matriz de poder social que o sustenta.

A retomada de um projeto "desenvolvimentista" do fortalecimento da competitividade da cidade enquanto resposta aos desafios da globalização, como se diz hoje faz-nos suspeitar que o "novo modelo estratégico" possa ser mais antigo do que gostariam aqueles que o (re?) inventaram (idem). Apesar de uma nova estrategia de marketing e de todo um discurso democrático e social ${ }^{11}$ (parte do marketing), apresenta uma série de "ingredientes" bastante conhecidos quando recordamos as experiências dos "grandes" planos da época de euforia planejadora.

10 Vide sobre este assunto Randolph (1996 b)

11 “A organização do Plano teve como princípio básico a vontade expressa de abrir um diálogo direto com os cidadãos e com as instituições que os representam. Essa comunicação direta é que vai permitir responder aos anseios da cidadania e colaborar para que esta realize esforços e assuma os compromissos para a execução do Plano. Não se trata de um plano de governo. Não são diretrizes impostas, ações descoordenadas ou isoladas, necessidades abstratas ou desejos impensáveis. São estratégias assumidas, programas de consenso, ações com objetivo, definindo necessidades expressas e consensuais, são projetos exeqüíveis" (Prefeitura da Cidade do Rio de Janeiro, 1996: 11-12) 
A história da formulação do Plano Estratégico demonstra tais características: "No dia 22 de novembro de 1993, o governo da cidade do Rio de Janeiro assinou um acordo com a Associação Comercial (ACRJ) e a Federação das Indústrias do Rio de Janeiro (FIRJAN) para promover um Plano Estratégico para a cidade do Rio de Janeiro (PECRJ)" (VAINER, 1996: 1 - a tradução é nossa). Estas duas entidades de classe e a Prefeitura constituíram os assim chamados Promotores do Plano. O Consórcio Mantenedor do PECRJ, onde ACRJ e FIRJAN lideraram mais 40 empresas, foi instalado em 4.2.1994 com a responsabilidade de levantar fundos para a realização de todas atividades, especialmente para a contratação de uma firma de consultoria da Catalunha, profissionais que assumiram o Comitê Executivo do PECRJ e outros consultores particulares. Como órgão de mais alta representação e autoridade da cidade foi, em 31.10.94, instalado o Conselho da Cidade.

A "concretude real" dessa "participação" pode ser mostrada através dos seguintes dados: o Conselho da Cidade contava com 305 pessoas, 109 pessoas ajudaram na elaboração do assim chamado Diagnóstico da Cidade, 323 na análise de propostas para a cidade e 25 especialistas elaboraram estudos.

Observando os Promotores, a orientação política da Prefeitura e os segmentos sociais que foram mobilizados para sua elaboração, o Plano "pode ser visto, sem questão, como uma sistematização da visão e do projeto da cidade de um expressivo setor da sua elite"(idem: 2). Pela sua aparência, poderíamos até qualificá-lo como uma grande "farsa"; mas acreditamos que nossa análise deve ser mais profunda. É possível dizer que a "novidade" do Plano - se o há - não se localiza na $1^{\text {a }}$ Arena do discurso político, mas na articulação entre as diferentes forças sociais, na formação da matriz dominante ( $2^{\mathrm{a}}$ Arena) onde se encontram novidades do discurso das tradicionais e corporativistas associações empresariais que permitem uma substantiva ampliação das forças sociais que apoiam o Plano (uma boa parte da sociedade civil organizada preocupada com as condições de segurança e qualidade de vida "cariocas"); é com estes agentes - na ausência dos partidos políticos e de outras forças sociais - que se articula uma nova matriz do poder social: a das elites (idem).

O Plano torna-se, então, o principal instrumento da afirmação de uma nova matriz do poder social; da construção e/ou consolidação de uma hegemonia ideológica que passa por uma ampla retórica social e participativa. Participação, que, por sua vez, segue o caminho "estratégico" do Plano com sua alta seletividade, que apenas admite como interlocutor legítimo aquele que negligencia a existência de conflitos e contradições que dificilmente serão superados pelas medidas propostas ${ }^{12}$.

Politicamente, o Plano é um acordo estratégico entre grupos da elite, limitado às condições gerais da "competitividade carioca", que - para legitimar sua dominância a nível local - precisase projetar como um suposto "consenso" amplo da sociedade carioca inteira - aliás, por sua vez, uma velha estratégia ideológica.

A política como elemento da afirmação da matriz do poder social

A investigação das "relações" entre PECRJ e Programa Favela Bairro mostra uma constelação de acordos que incorporam o Programa como parte de estratégias de sua legitimação perante classes e segmentos sociais excluídos destes acordos. Daí, pelo menos ao nível do discurso político público, a necessidade de insistir, anacronicamente, na promessa da "integração" das favelas aos bairros.

Não obstante, a importância do Programa não se esgota aqui; era crucial o discurso ser

12 Vide a troca de cartas entre o Secretário Geral do Plano e o diretor do IPPUR após o desligamento do Instituto do Conselho da Cidade: 
acompanhado por uma atuação e seus resultados imediatos. Pois, conforme Castells e Borja (1996: 152-166), existem três fatores relacionados ao próprio processo de implementação que muitas vezes nao são, como dizem, levados suficientemente em consideração. Para nossos propósitos, é suficiente observar o primeiro fator apesar de que o segundo guarda relação com o Programa Favela Bairro (questão da imagem da cidade que ela tem de si mesma):

Em primeiro lugar, a definição de um Projeto de Futuro só será eficaz se mobilizar, desde o seu momento inicial, os atores públicos e privados e concretizar-se em ações e medidas que possam começar a implementarse de imediato. Somente assim, verificar-se-á a viabilidade do plano, gerar-se-á confiança entre os agentes que o promovem e poder-se-á construir um consenso público que derive numa cultura cívica e num patriotismo de cidade. Esta será a principal força de um plano estratégico. (destaque nosso)

Temos aqui o caso já mencionado anteriormente, onde a "hierarquia" entre as três ARENAS vai sendo substituída por um processo circular: procura-se obter a afirmação de uma matriz de poder social ( $2^{\mathrm{a}}$ Arena) através de ações bem sucedidas dos próprios aparatos do Estado ( ${ }^{\mathrm{a}}$ Arena). O Programa revela uma verdadeira "vocação estratégica" de fornecer elementos chaves para esta matriz de poder social (vide RANDOLPH, 1996b):

- os autores apontam a questão da temporalidade do plano como questão verdadeiramente estratégica para a consolidação de uma matriz; neste sentido, o Programa Favela-Bairro, que já tinha passado por uma primeira fase de experimentação em 1994/95, ofereceu-se como medida que prometeu resultados rápidos;

- a área de atuação do Programa (favelas) é igualmente estratégico na medida em que representa uma atuação junto a uma população excluída da formulação do Plano; fornece uma certa sustentação material ao conteúdo ideológico do objetivo central - "tornar o Rio de Janeiro .... socialmente integrada ..." - que permite sua apropriação na construção de um discurso - até certo ponto - hegemônico como assistimos durante a última campanha eleitoral;

- constrói-se, assim, uma confiança no mínimo questionável entre aqueles que promovem o Plano com aqueles que não foram consultados; chega a criar-se um certo consenso e uma nova "leitura" da cidade - e da favela como bairro; parte da cidade - uma identificação que os autores chamam de "patriotismo de cidade";

- seu caráter quase que instantâneo ("learning by doing") e "obreiro" - de propor intervenções com imediata visibilidade - tiveram certamente uma considerável contribuição para seu rápido reconhecimento;

- enfim, apesar da ausência quase completa, com exceção de poucos casos, da "participação das comunidades", uma ampla mobilização da qual participam setores de profissionais até então pouco envolvidos na solução concreta dos problemas de urbanização de favelas, renova o interesse da universidade e de camadas da intelectualidade (mesmo a crítica) como agentes de divulgação e legitimação do Programa e seus contribuições "indiretas" (para a matriz de poder social).

\section{Cidade competitiva ou cidade da inclusão/exclusão social}

Como já mencionamos anteriormente, a formação da nova matriz do poder social faz-se na base de uma perspectiva compartilhada entre seus integrantes a respeito da agenda política e da representação da realidade urbana. No atual item procuramos explicitar esta visão da "cidade competitiva" - presente no Plano Estratégico - e confrontá-la com uma percepção que procura realçar seu caráter conflitante e segregador que elaboramos para poder avaliar as potencialidades do Programa Favela-Bairro. 


\section{A cidade como bem estratégico}

Retomamos aqui uma discussão encetada em Randolph (1996b). A definição de cidade que se expressa no projeto político hegemônico e que possibilitou os acordos estratégicos entre os diferentes agentes que sustentam o Plano Estratégico é a de um bem estratégico. É sobretudo a revalorização da cidade dos negócios, do terceiro setor superior (serviços avançados para as empresas $^{13}$, "business parks", áreas de C\&T, oferta cultural de qualidade etc.), que permite o "city marketing", a atração de investimentos e "citizen users" solventes (vide BORJA, 1994: 7-8). Uma cidade para o consumo global para uma população que, em parte, não vive nela, quando muitos dos residentes são excluídos dela.

A grande metrópole latino-americana representa potencialmente um "bem estratégico" para atrair não apenas o consumo sofisticado, mas também os setores estratégicos da nova produção pós-fordista (os mencionados setores de serviços pós-industriais, indústria cultural etc.); mas, não está plenamente capacitada para exercer estas funções; portanto, encontra-se em crise: por um lado uma crise de suas funções, por outro, da governabilidade e de integração sócio-cultural (idem: 8).

Revela-se, assim, uma posição relativamente frágil do Programa, compensada certamente, por ora, pela presença do órgão internacional de financiamento, o Banco Interamericano de Desenvolvimento (BID), que vem assegurando sua continuidade. Porém, o Programa poderá sofrer o conhecido processo de esvaziamento e desaceleração quando perde ainda seu "apelo popular", na medida em que os resultados que a população realmente sente, ficam, a médio prazo, atrás das expectativas geradas pelos objetivos publicamente anunciados - a "integração" das favelas aos bairros. Uma ampla e pública insatisfação zelaria, certamente, o destino de mais uma tentativa de melhorar as condições de vida nas favelas cariocas.

\section{A cidade como lugar de exclusão/inclusão social}

A busca por uma compreensão "alternativa" da realidade urbana, da segregação social e espacial, dos processos de exclusão e da violência tem, portanto, não um fim tradicionalmente acadêmico; mas, esta visão só fará sentido se tiver "eficácia política"; isto é, se ir de encontro com perspectivas de forças sociais que poderão travar concretamente a luta pela definição na $3^{a}$ Arena política.

Nosso esforço de sistematização precisa ser visto desta maneira; parte de um ponto de partida diferente ao qual atribui alguma "capacidade política" de articulação em torno do Programa Favela-Bairro. Não pretende, então, oferecer uma conceituação geral da problemática da exclusão. Considera-se necessário e suficiente, neste contexto, sistematizar algumas idéias já relativamente elaboradas sobre este fenômeno que mantêm relação mais próxima com as intenções do Programa. Sem, entretanto, ficar por demais preso a ele.

Será particularmente importante, portanto, elaborar uma visão sintética ${ }^{14}$ que possa qualificar melhor a ordem da grandeza e profundidade da intervenção proposta pelo Programa FavelaBairro. Uma perspectiva que, apesar do caráter amplamente retórico, como várias vezes repetimos, do discurso da "integração", procura não apenas identificar as diferenças em termos aparentes de condições materiais da vida da população, mas também entrar no debate sobre os

13 Os assim chamados serviços pós-industriais ("producer services"), vide Lash e Urry (1994: 193 ss).

14 De preferência em forma de um quadro sistematizado, semelhante ao dos elementos do Programa Favela Bairro, que possibilita uma comparação com suas esferas da intervenção. 
mecanismos sociais de exclusão/inclusão ${ }^{15}$ que estão por detrás das manifestações mais superficiais. Optamos, para isto, por uma perspectiva da "cidade excludente".

Inicialmente, exclusão social pode ser vista como "impossibilidade de poder partilhar da sociedade .. [que] leva à vivência da privação, da recusa, do abandono e da expulsão, inclusive com violência, de uma parcela significativa da população. Não se trata de um processo individual, embora atinja pessoas, mas, de uma lógica que está presente nas várias formas de relações econômicas, sociais, culturais e políticas da sociedade brasileira. Esta situação de privação coletiva é que se está entendendo por exclusão social" (SPOSATI, 1996: 13).

Não deixa de ser problemático compreender "exclusão" quase imediatamente como "privação"; portanto, não seguiremos as diferenciações que Sposati introduz a respeito de diferentes formas de exclusão (e inclusão, pois deve ser visto como um processo gradual, de graus). A construção de uma visão ("modelo") sintética e sistemática partirá da identificação de certas dimensões (sociais) da exclusão/inclusão ${ }^{16}$ que serão desdobradas em determinadas categorias como estruturantes do espaço urbano

Observando as "esferas" 17 das sociedades ocidentais (capitalistas) contemporâneas, pode-se distinguir três dimensões da exclusão/inclusão inerentes:

i. à relação entre Estado e sociedade (civil) que diz respeito aos direitos e deveres dos cidadãos e dos serviços do Estado prestados à sociedade ${ }^{18}$;

ii. à relação entre sistema econômico (mercado) e os trabalhadores e consumidores com os quais mantêm "intercâmbio" (mediado por dinheiro e poder) privilegiado; e

iii. às relações dentro da própria sociedade, das suas formas de articulação e integração.

Vejamos com mais profundidade:

(i) Cidadania liberal, democracia e atendimento às demandas sociais: Exclusão/inclusão (político) ao nível do relacionamento do "cidadão" com a autoridade estatal

Em Estados do bem estar liberal-democráticos a noção de cidadania envolve os três aspectos do relacionamento dos cidadãos com a autoridade estatal (idem 269 e ss) ${ }^{19}$ :

(i) vindo da tradição da teoria política do liberalismo, os "cidadãos" constituem a principal fonte da vontade política coletiva, na formação da qual eles são chamados a participar sob várias formas. institucionais;

(ii) com raízes na teoria da democracia, são os cidadãos os próprios "sujeitos" "contra quem essa vontade pode ser imposta e cujos direitos e liberdades civis, ao constituírem uma esfera autônoma de ação social, cultural, política e econômica 'privada', impõem limites sobre a autoridade do Estado"; ao atribuir ao "povo" sua principal fonte de autoridade, instaura institucionalmente mecanismos de governo democrático e de representação que asseguram sua "voz ativa": são o sufrágio universal, a liberdade partidária, as eleições gerais, a regra da maioria e outros;

(iii) com origens na teoria do Estado do bem estar, eles "são clientes que dependem dos serviços, dos programas e dos bens coletivos fornecidos pelo Estado, para garantirem os seus meios de sobrevivência e de bem-estar material, social e cultural em sociedade"; o

15 Já que nos não conseguimos seguir a lógica da "integração"; pois é mesmo questionável, se uma "integração sistêmica" da população favelada é um objetivo que se deve perseguir e que esta população mesma quer; temos indicações para acreditar que não.

16 Vide a respeito da recuperação e do debate de abordagens explicitamente relacionadas com a exclusão social o trabalho de Bessa (1996)

17 Não negamos, nesta "demarche", uma certa influência habermasiana, vide o trabalho de Haberrnas (1989); algumas das idéias desta teoria mais interessantes para nossos propósitos são discutidas em outro trabalho (HABERMAS, 1990: 65-103)

18 Como diz Offe (1989: 269). "os cidadãos estão estruturalmente relacionados à autoridade estatal basicamente de três maneiras: eles são (i) coletivamente os criadores soberanos da autoridade estatal; (ii) potencialmente ameaçados pela força e coerção estatal organizada; e (iii) dependentes dos serviços e provisões organizados pelo Estado.

19 Sabemos que o Estado brasileiro não pode ser compreendido exatamente enquanto de bem-estar liberal democrático nos moldes dos países industrializados. 
Estado providencia certas condições de "garantia civil" na medida em que os cidadãos dele dependem devido à "perda tanto das formas feudais paternalistas de 'bem estar' quanto da autarquia econômica individual que a natureza de controle pelo mercado do capitalismo industrial é incapaz de compensar totalmente".

Não cabe aqui questionar a estabilidade e viabilidade da "arquitetura de um sistema político composto destes três componentes estruturais", como faz Offe (idem: 271) ao apontar que há uma tensão e tendência à instabilidade (conflitos) entre os três elementos.

Mais pragmaticamente, para encontrar "padrões de exclusão/inclusão" nesta dimensão, buscamos identificar as manifestações concretas dos relacionamentos entre cidadão e autoridade estatal em relação a estes três elementos (às vezes também enunciados como os três direitos básicos ${ }^{20}$ - civil, político e social). A própria formulação dos direitos tem certamente sua própria importância, enquanto condição necessária, para a questão da exclusão; mas a realidade social do exercício do poder (em ambas as direções) e de seus resultados precisa ser observada através de componentes que explicitam concreta e empiricamente os relacionamentos.

Assim, a visão dos três componentes liberal, democrático e (de bem estar) social pode ser apropriada analiticamente como "esquema formal" de formas de "convivência" entre sociedade e Estado e permitir a distinção de diferentes graus de exclusão/ inclusão das pessoas (que serão "cidadãos" em maior ou menor grau).

Em uma primeira tentativa de sistematização, a "expressão concreta" dos relacionamentos pode ser esquematizada conforme mostra a tabela a seguir. Acrescentamos um novo componente que surge com maior força nas últimas duas décadas: o direito ambiental como nova fonte de direitos e deveres do cidadão.

O "grau de exclusão/inclusão" (nesta dimensão, do/no poder social) poder-se-ia "calcular", então, a partir da verificação da presença/ausência de condições concretas acima esboçadas; presença não significa aqui, necessariamente, que o fenômeno precisa ser encontrado dentro da favela; a existência de equipamentos fora da favela, por exemplo, e de fácil acesso poderá ser contemplada como atendimento conforme os direitos citadinos.

\section{(ii) Mercado: Exclusão/inclusão (econômico) das relações do mercado (dinheiro e poder)}

Uma outra modalidade (dimensão) de exclusão/inclusão estabelece-se em relação ao(s) mercado(s). A vida moderna tem como uma das suas principais características o avanço das relações abstratas mercantis em detrimento de outras formas de convivência social e econômica. Estar "presente" nos mercados é um dos pressupostos mais importantes para ser considerado "integrado" à sociedade inteira (uma parte da "integração sistêmica"(GIDDENS, 1989). Da mesma maneira como foi o caso dos relacionamentos entre cidadãos e autoridade estatal, a relação sujeito - mercado é abstrata, mediada por meios de troca também abstratas: dinheiro e poder. Uma certa "concretização" seria possível, quando se observa até onde a vida econômica e social da população esteja se inscrevendo nos principais mercados e suas relações. Mesmo sem querer precipitar as conclusões da avaliação, pode-se dizer que a exclusão/inclusão da população favelada será particularmente sentida em relação aos mercados.

\section{(iii) Exclusão/inclusão (social) nas formas de reprodução social (tradição, socialização e formação de personalidade)}

Além dos relacionamentos dos cidadãos/clientes como Estado e dos trabalhadores/consumidores com o mercado, apontamos acima as próprias relações dentro da "sociedade", expressas através de suas formas de articulação e integração, como uma outra possível dimensão de exclusão/inclusão.

20 É necessário, portanto, investigar o sistema legal e as regras por ele estabelecido de convívio social; a lei básica, a Constituição, torna-se, então, fonte primária para nossa análise como veremos mais adiante. 
Salta aos olhos que não é uma dimensão independente das duas já trabalhadas: ao contrário, a história da modernização econômica e burocrática mostra o avanço de relações "funcionais" para dentro da estrutura tradicional das sociedades. Mas, apesar de poderem ser consideradas dominantes - e, neste sentido, são elas as principais responsáveis pela exclusão/inclusão -, essas relações mediadas por dinheiro e poder não se tornaram exclusivas; isto é, não substituíram por inteiro formas de reprodução social que continuam a seguir uma lógica diferente da instrumentaleconômica e administrativa.

Esta outra esfera é - seguindo Habermas - a cotidiana, o mundo da vida das pessoas, que mantém uma certa autonomia como "lugar" ${ }^{21}$ da reprodução social; é aqui, em última instância, onde as formas de exclusão/inclusão do poder sistêmico e do dinheiro se concretizam no embate com a lógica própria de "inserção/exclusão social" de cunho comunicacional, do "agir comunicativo".

Neste "mundo da vida simbolicamente estruturado" os componentes estiveram originalmente entrecruzados e jamais devem ser entendidos como sistemas que formam ambientes uns para os outros. São a cultura (encarnada em formas simbólicas); a sociedade (encarna-se nas ordens institucionais ou nas entrançadas de práticas e costumes regulados normativamente); e as estruturas de personalidade (encarnadas literalmente no substrato dos organismos humanos).

Na prática do cotidiano, "todo o sentido conflui para o mesmo ponto" (HABERMAS, 1990), não há distinção, separação. Não há dualismo, no sentido de Giddens (idem) ${ }^{22}$, mas dualidade; ou, no caso de Habermas não há três pólos, mas triplicidade. Não obstante, estes componentes formam grandezas distintas por causa (ontologicarnente) dos aspectos espaciais e sociais de suas encarnações.

Assim, indo além de Giddens, Habermas permite distinguir, mesmo a nível da integração social, diferentes horizontes (temporais e espaciais): (i) tradições culturais; (ii) sociedades e (iii) estruturas de personalidade.

Cabe, então, caracterizar a exclusão/inclusão como processo e resultado, diferentemente (mas de maneira complementar) em distintas "escalas" tanto de articulação social, econômica e política como de manifestação territorial.

\section{(iv) A “cidade da exclusão": Sínteses territoriais de exclusão/inclusão}

A "cidade da exclusão" é uma só: não existem os "excluídos" sem aqueles que os excluem mesmo quando são os próprios "excluídos" aqueles que se excluem dos "incluídos". Não trabalhamos, portanto, com hipóteses dualistas (formal/informal) ou de partição ("cidade partida") do tecido urbano. Desigualdades, segregação. conflitos e contradições, dominação e submissão etc. pressupõem essa totalidade; mas permitem, também, operar analiticamente com determinadas partes, parcelas.

Por ser no território que todas as diferentes "formas" e "lógicas" de exclusão/, inclusão se articulam, a compreensão de suas características e dinâmicas exige um quadro complexo de categorias, componentes e elementos que possam representar tanto as diferentes lógicas de racionalidades (instrumental e comunicativa), de escalas sociais e territoriais diferenciais, de temporalidades distintas etc. É óbvio, que nossa reflexão vai poder se apoiar apenas em um modelo relativamente simples, mas que procura resgatar este caráter das múltiplas determinações do quadro de exclusão/inclusão em uma área de cidade selecionada para a investigação. Restringimonos, ainda, à consideração de lugares de moradia (popular) sem a presença de equipamentos maiores de produção ou distribuição ${ }^{23}$.

Para isto, o esquema (matriz) na página a seguir lança mão de características (categorias):

21 Que consiste de muitos "lugares" ou até "regiões", conforme elaborou GIDDENS em sua teoria de estruturação vide idem;

22 Vide especialmente o primeiro capítulo.

23 É uma restrição que parece oportuna na medida que nossa atenção está dirigida para o Programa Favela Bairro. 
(i) no primeiro eixo (vertical), que aponta para certas diferenciações sócio-territoriais e temporais, diferencia-se entre indivíduos ("agentes", famílias), grupos de convivio mais ou menos próximo e permanente (comunidades menores ou maiores, sociedade local) e relacionamentos que ultrapassam localizações específicas e se generalizam (parcialmente) em espaços maiores, que transcendem as relações presentes também temporalmente (o urbano e seus segmentos, as tradições, a cultura);

(ii) no outro eixo (horizontal), distingue-se as categorias a partir de uma certa "hierarquia" territorial-material; porém atravessada pela contemplação das diferentes lógicas sociais $^{24}$. Assim, seguem da caracterização da "autonomia cotidiana" (o nível mais próximo à vida social cotidiana, mas que expressa também a imposição e/ou apropriação de determinações mais abrangentes, como submissão a dispositivos legais, usufruto de serviços coletivos etc.) e do "ambiente cotidiano" (que congrega as condições materiais e ambientais destas vidas cotidianas) à da "inserção nos mercados" (que representa a interface entre as lógicas instrumental e comunicativa na "esfera privada" - agente e família).

(iii) num patamar que não se refere mais às "unidades básicas" do agente e da família, mas que determina uma boa parte de seu "ambiente cotidiano", introduzimos as categorias de "acessibilidade e circulação" (que diz respeito às condições coletivas dos acessos) e de "conforto ambiental-urbanístico" (características físico-naturais e do ambiente construído da localização em geral - sítio).

(iv) na coluna seguinte, aponta-se as condições físico-materiais, econômico-sociais do "desenvolvimento humano-social" que estão constituídas por equipamentos coletivos (educação, saúde, segurança etc.) e serviços públicos (de ensino, medicina, policiamento etc.) ofertados de uma forma genérica (porém, que podem ser de acesso seletivo quando exigirem certa autonomia cotidiana para seu usufruto - vide escola, hospital etc. privados). E, finalmente, tem-se como possível categoria de exclusão/inclusão a "expressão política" da sociedade (e de seus "membros") que mescla, simultaneamente, elementos institucionais (existência e presença do poder público, manifesto em equipamentos e serviços; de partidos políticos etc.) com outros da organização coletiva (formas de auto-organização, associações; movimentos etc.)

\section{CATEGORIAS, COMPONENTES E ELEMENTOS DE EXCLUSÃO/INCLUSÃO}

\begin{tabular}{|c|c|c|c|c|c|c|c|}
\hline Categorias & $\begin{array}{l}\text { Autonomia } \\
\text { Cotidiana }\end{array}$ & $\begin{array}{l}\text { Ambiente } \\
\text { Cotidiano }\end{array}$ & $\begin{array}{l}\text { Inserção nos } \\
\text { Mercados }\end{array}$ & $\begin{array}{l}\text { Acessibilidade } \\
\text { e Circulação }\end{array}$ & $\begin{array}{l}\text { Conforto } \\
\text { Ambiental e } \\
\text { Urbanístico }\end{array}$ & $\begin{array}{l}\text { Desenvolvi- } \\
\text { mento Humano- } \\
\text { Social }\end{array}$ & $\begin{array}{l}\text { Expressão } \\
\text { Política }\end{array}$ \\
\hline $\begin{array}{l}\text { Urbano } \\
\text { (tradição, cultura) }\end{array}$ & $\begin{array}{l}\text { valores e } \\
\text { preconceitos } \\
\text { sociais (em } \\
\text { relação a gênero, } \\
\text { raça etc.); } \\
\text { discriminação } \\
\text { social (origem } \\
\text { social); } \\
\text { estigmatização }\end{array}$ & $\begin{array}{l}\text { caminhos } \\
\text { percorridos } \\
\text { diariamente } \\
\text { (para lugares } \\
\text { como escola. } \\
\text { trabalho, } \\
\text { compras etc.); }\end{array}$ & $\begin{array}{l}\text { "localização" dos } \\
\text { mercados }\end{array}$ & $\begin{array}{l}\text { inserção no } \\
\text { sistema viário } \\
\text { urbano; vias } \\
\text { de acesso } \\
\text { existentes } \\
\text { rede de } \\
\text { telefonia }\end{array}$ & $\begin{array}{l}\text { localização do } \\
\text { sítio. relevo, } \\
\text { riscos } \\
\text { ambientais } \\
\text { ambiente } \\
\text { construído (incl. } \\
\text { padrão } \\
\text { urbanístico) no } \\
\text { entorno. } \\
\text { bairro etc. }\end{array}$ & $\begin{array}{l}\text { escolas } \\
\text { postos de saúde } \\
\text { ambulâncias } \\
\text { creches } \\
\text { postos policiais, } \\
\text { bombeiros } \\
\text { meios de } \\
\text { transporte } \\
\text { praças, quadras } \\
\text { de esporte }\end{array}$ & $\begin{array}{l}\text { organismos do } \\
\text { Estado } \\
\text { institutos legais } \\
\text { partidos } \\
\text { entidades de } \\
\text { classe etc. } \\
\text { acessibilidade }\end{array}$ \\
\hline
\end{tabular}

24 Os eixos não representam bem uma única "dimensão"; mas um aglomerado de diferentes formas de estruturação e dinâmica da vida social e política; uma certa "heterogeneidade" entre os componentes é inevitável numa tamanha redução de complexidade dos fenômenos conceituados e observados. 


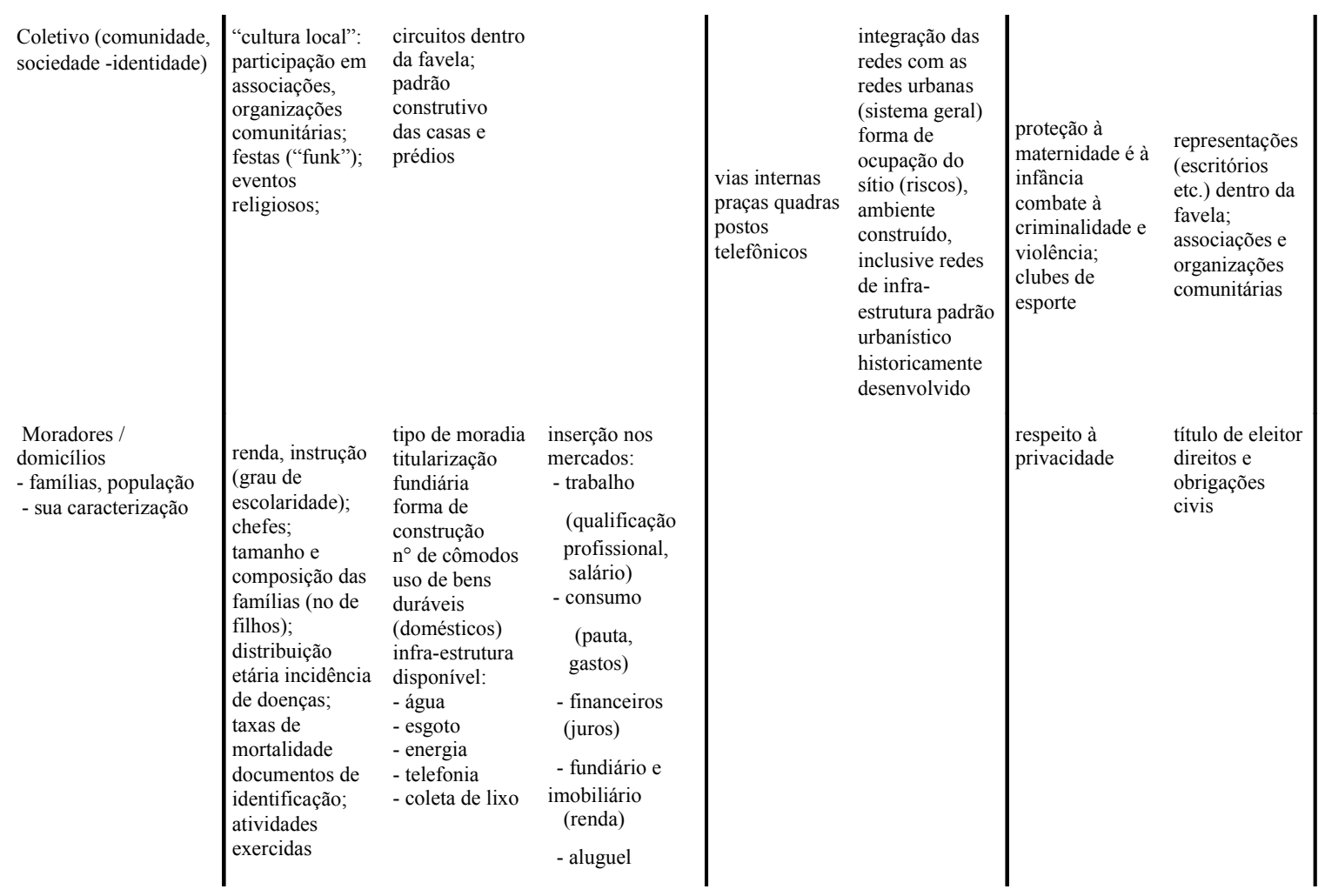

A Matriz "Categorias, Componentes e Elementos de Exclusão/Inclusão" apresenta apenas esquematicamente "variáveis" que podem vir a caracterizar a situação de exclusão/inclusão em uma determinada área (comunidade); no nosso caso, em favelas. Pretende mostrar que um quadro de exclusão/inclusão precisa ser traçado em diferentes patamares e esferas onde, inclusive, características de exclusão/inclusão podem ser antagônicas (já mencionamos a questão da "inclusão" nos mercados e seus possíveis efeitos "excludentes" para a vida coletiva).

Portanto, "a" cidade da exclusão muitas faces e facetas de inclusão pode ter.

\section{Conclusão: projetos políticos e potencial idades do Programa Favela-Bairro}

Resta cumprir, então, o último passo anunciado no início do presente trabalho: a partir do reconhecimento das limitações do programa - o que não é nenhuma crítica -, imaginarmos as potencialidades que poderiam surgir com uma ampliação de seu escopo. Porém, como estas mudanças dependem de condições políticas (e não apenas de possibilidades técnicas), nada asseguraria sua realização, se não acharmos manifestações políticas e sociais que possam ser os porta-vozes de uma reformulação substancial do Programa.

O Programa Favela-Bairro, como qualquer política governamental que pretende modificar o quadro de exclusão/inclusão em sociedades como a nossa, tem uma abrangência limitada. Mesmo assim, quando comparamos as esferas da intervenção .do Programa (Matriz no item 2b) com as categorias e patamares da exclusão/inclusão social (Matriz no item $4 \mathrm{~b}$ (iv)) fica evidente seu caráter seletivo, mas diversificado.

Em termos das categorias de exclusão/inclusão o Programa abrange uma série de elementos em Autonomia e Ambiente Cotidianos, relacionado a isto, na Acessibilidade e Circulação e Conforto Ambiental E não deixa de atingir determinados aspectos mesmo do Desenvolvimento Humano-Social. Complementarmente prevê medidas para melhorar a Inserção nos Mercados - se 
bem que os programas de renda são dirigidos, em boa parte, à "economia comunitária"

Como dissemos, a relativa diversificação dos objetivos e medidas manifesta-se de forma bastante seletiva; restringe-se a alguns elementos e deixa de fora outros de grande relevância. Por exemplo, nas categorias Autonomia e Ambiente Cotidianos a referência à titularização é tênue; o problema da propriedade (posse) tendencialmente não é atacado; padrões existentes de segregação (inclusive discriminação) social não são objeto de intervenção. Em relação à Inserção nos Mercados, as medidas Pouco devem provocar em relação à exclusão/inclusão na sua parte formal (trabalho, consumidor, investidor, tomador de empréstimo etc.) da mesma maneira como em Acessibilidade e Circulação as formas mais sofisticadas de comunicação (telefonia etc.) não são contempladas

Em relação ao Conforto Ambiental e Urbanístico as medidas apenas podem reduzir os riscos mais iminentes; a precariedade deste conforto tem sua origem na própria história da ocupação das áreas e parece de difícil correção. Na categoria Desenvolvimento Humano-Social caberia ainda uma melhor apreciação da disponibilidade do acesso a equipamentos e serviços no entorno da favela - onde segregação e discriminação social, preconceitos, etc., podem tornar difíceis seu verdadeiro usufruto; particularmente grave apresenta-se, em muitas favelas, o quadro da situação da criminalidade e violência (p.ex. narcotráfico) que cria uma forma própria de exclusão; seu combate certamente é o mais difícil e necessitaria uma atuação a longo prazo. Enfim, as limitações à Expressão Política da população favelada restringem sua participação ativa nas instituições democráticas; e vice versa: as restrições à participação (desde a situação em relação a Autonomia e Ambiente Cotidiano, sua Inserção nos Mercados etc.), que têm várias origens, permitem a população apenas uma restrita expressão política.

Essas são apenas algumas primeiras e superficiais indicações que mostram as limitações e lacunas, mas, ao mesmo tempo, também as potencialidades do Programa. Não nos parece fora de propósito achar que podem ser, pelo menos parcialmente, incorporadas ao Programa dentro do espírito dinâmico e de sucessivas reformulações que caracterizam a sua trajetória.

De fato, a história recente das reformulações do Programa após a criação da Secretaria Municipal de Trabalho e outras medidas indicam que de alguma forma se seguiu, mesmo parcialmente, este caminho. Não caberá mais ao presente trabalho acompanhar essas mudanças.

DETERMINAÇÕES ESTRATÉGICAS E POTENCIALIDADES DE TRANSFORMAÇÃO DO PROGRAMA FAVELA-BAIRRO

Resumo - O trabalho procede a uma meticulosa análise das proposições do Programa Favela Bairro e aponta que, como qualquer política governamental que pretende modificar o quadro de exclusão/inclusão em sociedades como a brasileira, tem uma abrangência limitada. Mesmo assim. quando comparamos as esferas da intervenção do Programa com as categorias e patamares da exclusão/inclusão social fica evidente seu caráter seletivo, mas diversificado.

STRATEGIC DETERMINATIONS AND POTENCIALITIES OF CHANGES AT FAVELA-BAIRRO PROGRAM

Summary - This paper makes a meticulous analysis on the Favela-Bairro Program propositions and points out that, as any government policy which intends to modify the exclusion / inclusion framework in societies: Societies like the brazilian, has a limited range. Even so, when we compare the Program scales of intervention with the categories and paths of social exclusion / inclusion its selective, but diversified, character shows off.

\section{Bibliografia}

BESSA, E. (1996): Programa Favela-Bairro, uma proposta de política urbana: inovadora? Trabalho apresentado no IV Seminário de História da Cidade e do Urbanismo, Rio de Janeiro 27 a 29.11 .1996

BORJA, J. (1994): Notas sobre ciudades, gobiernos locales y movimientos populares. Revista EURE, vol. XX, no. 59, pp. 7-20

CASTELLS, M. e BORJA, J. (1996): As cidades como atores políticos. Novos Estudos Cebrap, No. 45, julho, p. 152-166 
GIDDENS, A. (1989): A constituição da sociedade. São Paulo: Martins Fontes.

HABERMAS, J. (1990[1988]): Pensamento pós-metafisico. Estudos filosóficos. Rio de Janeiro: Tempo Brasileiro.

HABERMAS, J. (1989[1981]): Teoria de la acción comunicativa (2 vols.). Madri: Taurus.

LASH, S., URRY, J. (1994): Economies of signs \& space. London e.o.: Sage Publ.

OFFE, C. (1984): Problemas estruturais do Estado capitalista. Rio de Janeiro: Tempo Brasileiro.

(1989): Capitalismo desorganizado. Transformações contemporâneas do trabalho e da política. São Paulo: Brasiliense.

(1991) Algumas contradições do Estado social moderno. In idem, Trabalho e sociedade, Vol II Perspectivas. Rio de Janeiro: Tempo Brasileiro.

OFFE, C. e RONGE, V. (1984) Teses sobre a fundamentação do conceito de "Estado capitalista" e sobre a pesquisa política de orientação materialista. In: Offe, C. Problemas estruturais do Estado Capitalista. Rio de Janeiro: Tempo Brasileiro.

Prefeitura da Cidade do Rio de Janeiro (1996): Plano Estratégico da Cidade do Rio de Janeiro - Rio sempre Rio. Versão resumida . Rio de Janeiro.

RANDOLPH, R. (Coord.) (1996a): Avaliação de políticas públicas: sugestões metodológicas a partir do caso do Programa Favela-Bairro. Rio de Janeiro: IPPUR/UFRJ.

RANDOLPH, R. (1997): Plano estratégico e urbanização de favelas no Rio de Janeiro: Análise de aspectos estratégicos do Programa Favela Bairro. Trabalho apresentado no VII Colóquio sobre Poder Local, Salvador.

(1996b): Acordos estratégicos ou alianças comunicativas: Formas alternativas de gestão e planejamento urbano? Trabalho apresentado no XX Encontro Anual da ANPOCS, $\mathrm{Caxambu} / \mathrm{MG}$.

(1995a): O planejamento comunicativo é possível? Indagações e reflexões sobre novas formas de articulação entre espaço, Estado e sociedade no Brasil. Trabalho apresentado no XIX Encontro Anual da ANPOCS, Caxambu/MG.

(1995b): "American Way" e redes brasileiras. Trabalho apresentado no VI Encontro Nacional da ANPUR, Brasília.

(1994a): Gestão comunicativa versus gestão participativa: Novas formas de responsabilidade política ou velhas irresponsabilidades? Trabalho apresentado no XXIII Encontro Nacional da ANPOCS, Caxambu.

(1994b): Novos agentes, novas fronteiras e novas espacialidades - umas reflexões sobre a sociedade brasileira contemporânea. Trabalho apresentado no Workshop "Avaliação do Planejamento Urbano e Regional: Propostas para o Brasil Urbano no Final do Século", Gramado/RS: ANPUR.

SIBLEY, D. (1995): Geographies of exclusion. London and New York: Routledge.

SPOSATI, A. (Coord.) (1996) Mapa da exclusão/inclusão social da cidade de São Paulo. São Paulo: EDUC.

VAINER, C.B. (1996): Participation, poverty, and environment in the Strategic Plan for the city of Rio de Janeiro. Paper presented at the Conference The Future of the City: Urban Change, the Environment, and Poverty, Cornell University, Ithaca, N.Y.,June, 10-14. 